Association for Information Systems AIS Electronic Library (AISeL)

AMCIS 2004 Proceedings

Americas Conference on Information Systems

(AMCIS)

December 2004

\title{
Customer Satisfaction with Electronic Service Encounters
}

Nelson Massad

Florida Atlantic University

Robert Heckman

Syracuse University

Kevin Crowston

Syracuse University

Follow this and additional works at: http://aisel.aisnet.org/amcis2004

\section{Recommended Citation}

Massad, Nelson; Heckman, Robert; and Crowston, Kevin, "Customer Satisfaction with Electronic Service Encounters" (2004). AMCIS 2004 Proceedings. 485.

http://aisel.aisnet.org/amcis2004/485

This material is brought to you by the Americas Conference on Information Systems (AMCIS) at AIS Electronic Library (AISeL). It has been accepted for inclusion in AMCIS 2004 Proceedings by an authorized administrator of AIS Electronic Library (AISeL). For more information, please contact elibrary@aisnet.org. 


\title{
Customer Satisfaction with Electronic Service Encounters
}

\author{
Nelson Massad \\ Florida Atlantic University \\ nmassad@fau.edu
}

\author{
Robert Heckman \\ Syracuse University \\ rheckman@syr.edu
}

\author{
Kevin Crowston \\ Syracuse University \\ crowston@syr.edu
}

\begin{abstract}
Customer relationship management has become an integral component for online service providers such online book retailers, online stock brokers, online bankers, and so forth. This paper investigated the aspects of individual online transactions (i.e., electronic service encounters) that are most likely to satisfy customers, thereby increasing the likelihood of building and maintaining relationships with customers. For this study, 513 respondents reported behaviors, perceptions, beliefs, events, features, characteristics, attributes, situations, and so forth that expressed respondents' perceptions of satisfaction or dissatisfaction with electronic service encounters. Content analysis of these customer-reported incidents with online service providers yielded 3 meta-categories, 6 categories, and 33 sub-categories. The taxonomy developed in this study therefore offered an insight into the specific events that contributed to the satisfaction or dissatisfaction of customers when they engaged in transactions with online service providers.
\end{abstract}

\section{Keywords}

electronic service encounter, customer satisfaction, electronic customer relationship management

\section{INTRODUCTION}

Building and maintaining relationships with existing customers is very important for service providers because it is more cost effective to retain existing customers than to acquire new ones. Online service providers lose $\$ 20$ to $\$ 80$ on each customer the first year because of the high cost of acquiring a customer, but can make up for the loss in the long run by retaining loyal customers (Reichheld and Schefter, 2000). Online service providers can spend up to 2.5 times more than their bricks-andmortar counterparts to acquire new customers (Kenny and Marshall, 2000). Furthermore, loyal customers engage in positive word-of-mouth communication and repurchase behavior, which means more revenue for the service provider in the long run (Morgan and Hunt, 1994, Sheth and Parvatiyar, 1995).

Realizing the potential benefits of establishing and maintaining relationships with customers, the electronic commerce field has seen a shift from a transaction-based model to a relationship-based model. The electronic commerce customer relationship management (ECCRM) has consequently emerged as a sub-field and continues to evolve within the information systems discipline (Romano and Fjermestad, 2001-2002).

The relationship with a service provider potentially develops after repeated experiences with a service provider. After a series of discrete satisfying experiences with a service provider, a customer crosses into what is referred to as the loyalty stage (Oliver, 1997, Oliver, 1999). Once a consumer reaches this loyalty state, a service provider is considered to have built a continuing association or bond (i.e., relationship) with the customer. It is therefore important to understand the aspects of individual transactions that are most likely to satisfy customers, thereby, increasing the probability of relationship development.

Ensuring that every customer experience or transaction is a satisfying one increases the likelihood of creating and maintaining a relationship with the customer. Given the importance of every transaction in establishing and maintaining a relationship, this study investigated the antecedents of customer satisfaction with business-to-customer transactions on the Web. 
This paper starts by presenting the theoretical background that guided this study. The paper then covers the method used for data collection followed by the procedures adopted for data analysis. Finally, the paper ends with a discussion of the results and its implications.

\section{BACKGROUND}

This section covers the service-encounter model that was used as a theoretical framework for this study. This section also sets forth the preliminary taxonomy and the types of services investigated in this study.

The service encounter model provides the study with a well-established framework to investigate discrete transactions. A service encounter is defined as the period of time that a customer interacts with a service (Shostack, 1985). The definition of a service encounter is broad and includes a customer's interaction with customer-contact employees, machines, automated systems, physical facilities, and any other service provider visible elements. On the Web, customers engage in service encounters with businesses by visiting their Web site, navigating through it, searching for product and service information, communicating with customer service representatives, and perhaps purchasing a product and/or service.

Researchers believe that the quality of the interaction between customers and service providers during the service encounter is important because it is at this level where customers judge the services provided to them (Collier and Meyer, 1998, Gronroos, 1990, Mohr and Bitner, 1995). They also agree that a service encounter is composed of a service outcome (i.e., what the customer receives during the exchange) and the process of service delivery (i.e., the way through which the outcome is delivered to the customer). They maintain that customer satisfaction with service encounters (i.e., transaction satisfaction) is a combination of the customer satisfaction with the service outcome and the customer satisfaction with the process of service delivery.

Moreover, customers with multiple encounters with a service provider will develop an overall perception of service quality and, hence, an overall satisfaction or dissatisfaction with the service provider. The following figure represents the conceptual framework that guided the study:

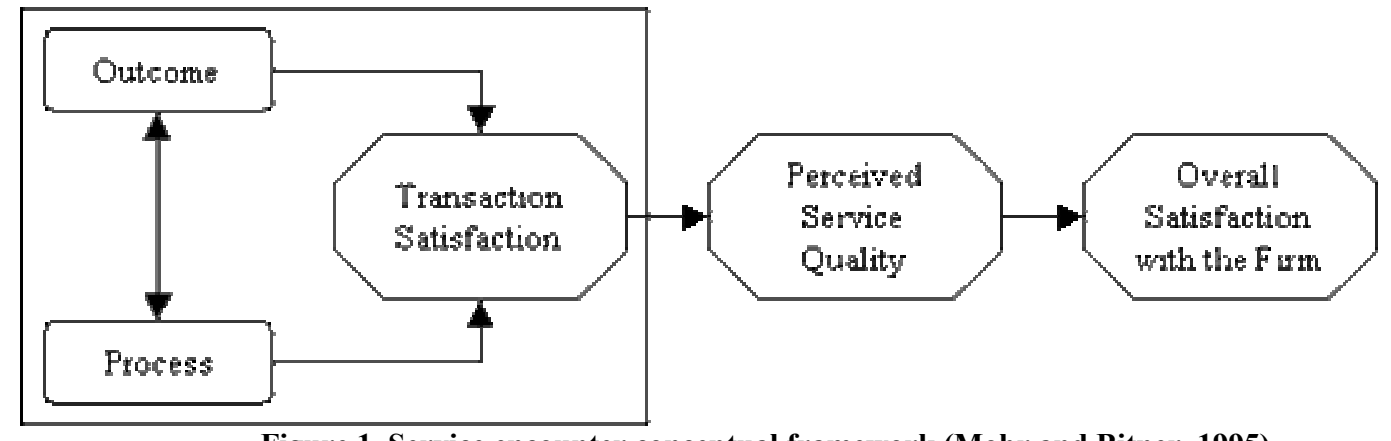

Figure 1. Service encounter conceptual framework (Mohr and Bitner, 1995)

This study concentrated on customer transaction satisfaction with online services on the Web (inside the box in Figure 1).

In one of the earliest studies of service encounters, Bitner, Booms, and Tetreault (Bitner, Booms and Tetreault, 1990) sought to identify the antecedents of customer satisfaction with service encounters in the airline, hotel, and restaurant industries from the customer's perspective. They identified three major categories (i.e., service delivery failures, special customer needs and requests, unprompted employee actions) and 12 sub-categories of antecedents of customer satisfaction. Further research has successfully shown these categories to be robust and valid across different industries: auto care/repair, financial services, educational services, health care, real estate (Gremler and Bitner, 1992), retail setting (Kelley, Hoffman and Davis, 1993), information technology help desks (Heckman and Guskey, 1998), and the gaming industry (Johnson, 1999).

The taxonomy has also been successfully tested across respondents: the employee's perspective as opposed to the customer's perspective. The taxonomy has also been tested using a different classification scheme from the one used in the original study (Heckman and Guskey, 1998). The findings of these studies support the validity and robustness of the three major categories in the taxonomy. The sub-categories, however, have been different and dependent on the context.

Given the electronic context of the study, several categories and sub-categories were added to the initial taxonomy. Trust, for instance, has been determined to be crucial in e-commerce (Gefen, 2002, McKnight and Chervany, 2002). In the bricks-andmortar environment, the physical presence of a service provider, including customer-contact personnel, the physical space, and the available products may inspire customer trust (Reichheld and Schefter, 2000). Transacting with an online service 
provider, however, involves a certain degree of risk and uncertainty because the behaviors of an online service provider are less guaranteed (Gefen, 2002, Gefen, Karahanna and Straub, 2003). Trust is a way to reduce the perceived risk and uncertainty of dealing with an online service provider (Gefen, 2000, Javenpaa and Tractinsky, 1999). The different types of trust as conceptualized by McKnight and Chervany (2002) were therefore included in the preliminary taxonomy. Further, we included Web site in the initial taxonomy since the first point of contact between a customer and a service provider in an online transaction is the Web site. The authors decided, however, that information technology interface was a more appropriate and a more inclusive category than Web site.

The following table presents the initial taxonomy of the antecedents of customer satisfaction with service encounters that was used as a guide for the present study.

\begin{tabular}{|c|c|}
\hline Category & Sub-category \\
\hline 1. Core service delivery failures & $\begin{array}{l}\text { A. Unavailable service } \\
\text { B. Unreasonably slow service }\end{array}$ \\
\hline 2. Customer's situation before the encounter & $\begin{array}{l}\text { A. Customer preferences } \\
\text { B. Deadline } \\
\text { C. Customer error } \\
\text { D. Novice } \\
\text { E. Past experience with service provider }\end{array}$ \\
\hline 3. Employee characteristics and behavior & $\begin{array}{l}\text { A. } \text { Competence } \\
\text { B. Attitude } \\
\text { C. Effective communication } \\
\text { D. Extraordinary behavior }\end{array}$ \\
\hline 4. Information technology interface & A. Perceived ease of use \\
\hline 5. Trust & $\begin{array}{l}\text { A. Disposition to trust } \\
\text { B. Institution-based trust } \\
\text { C. Trusting beliefs } \\
\text { D. Trusting intentions }\end{array}$ \\
\hline
\end{tabular}

Table 1. Initial taxonomy used for this study

The authors turned to the service-classification literature for a theoretical framework that helped determine the types of services to investigate for this study. The service-classification literature provides various taxonomies used to classify services along several dimensions. The authors reviewed several taxonomies developed within both the brick-and-mortar context (Lovelock, 1983, Schmenner, 1986, Wemmerlov, 1990) and the electronic context (Klein, 1998, Peterson, Balasubramanian and Bronnenberg, 1997). After selecting the different dimensions applicable to the electronic context, the authors identified two types of services to investigate for this study: product-related services (e.g., online purchasing of books, apparel, music CDs, videos) and pure services (e.g., online banking, online stock trading, online travel agents).

\section{METHOD AND PROCEDURE}

The goal of the data collection effort was to obtain a broad sample to build a taxonomy of antecedents of customer satisfaction with online service encounters. Data were collected through a self-administered Web questionnaire using the critical incident technique as the elicitation format. The critical incident technique is a systematic procedure for collecting events and behaviors that lead to the success or failure of a specific task (Bitner et al., 1990, Flanagan, 1954, Grove and Fisk, 1997, Ronan and Lathan, 1974). The aim of the critical incident technique is to collect very detailed descriptions or stories from respondents about a memorable experience. Respondents were consequently situated in a recent memorable experience that they themselves had experienced. Respondents were asked to think of a time when they have had what they believe to be a particularly satisfying or unsatisfying experience in the last three months with a [Web site, online purchasing, online auction, online banking, and so forth]. Respondents were then asked the following questions: 
1. How did the respondent evaluate the incident? [satisfying or unsatisfying]

2. When did the incident occur?

3. Describe the circumstances leading to the incident.

4. What happened exactly?

5. Who was involved?

6. How did the incident end?

7. Why did the respondent believe the incident to be satisfying or unsatisfying?

The purpose of the above questions was to get the respondent to provide a rich description of the incident. The respondents focus on describing the events and details of the incidents. All inferences, abstractions, and conclusions are done by the researchers (Bitner et al., 1990, Keaveney, 1995).

Respondents were solicited through a number of listservs and newsgroups on the Web to participate in the study. These mailing lists and newsgroups were publicly available (e.g., liszt.com, Yahoo.com, Google.com, Tile.net). Furthermore, students from several universities and online research panelists were also polled to participate in the study.

The data elicitation procedure resulted in 513 incidents. Of these incidents, 270 incidents were satisfactory and 243 incidents were unsatisfactory (refer to Table 2 for a complete breakdown of the sample).

\section{Data Analysis}

The purpose of the data analysis was to augment and refine the preliminary taxonomy of antecedents of customer satisfaction with online service encounters initially identified from the different literatures. This section describes the process followed by the authors during the data analysis phase.

Initially, the authors would read an incident to get a general sense of the different aspects of the service encounter the respondents were describing. The authors would then intently read the respondent's description of the service encounter to identify words, phrases, or sentences (i.e., utterances) that expressed the respondent's perception of satisfaction and dissatisfaction with a service encounter with an online service provider. Once identified, they were assigned codes or labels, which were meaningful names. Note that not all respondents' descriptions were related to their perceptions of satisfaction and dissatisfaction with online service encounters. There was some contextual information that was also coded (e.g., name of service provider, consequences, type of business).

An analytical framework for data analysis as outlined by Miles and Huberman (Miles and Huberman, 1994) was used. The framework begins by identifying the data to be analyzed, coding or tagging the data, and identifying patterns in order to provide an explanatory framework. The preliminary taxonomy (see Table 1) was used as a guide in analyzing the data. Through a deductive/inductive iterative process, the authors generated and refined categories and sub-categories in the taxonomy.

The process consisted of the following overlapping phases:

- An initial deductive approach to determine if each behavior, feature, event, situation, perception, and so forth described in each critical incident fit into a category of the preliminary taxonomy identified from the literature.

- An inductive approach in which new categories were added and unused categories discarded from the taxonomy as critical incidents were collected and analyzed.

- The deductive/inductive iterations continued until saturation of categories was reached.

Similar to Heckman and Guskey (Heckman and Guskey, 1998), this study used a faceted classification process. This process first identified the utterances (i.e., words, phrases, sentences) that expressed respondents' perceptions of satisfaction or dissatisfaction with electronic service encounters. These customer-reported utterances or descriptions were then classified into the sub-categories within the taxonomy. This allowed an incident to be classified in many sub-categories within the taxonomy, allowing the study to retain the richness of the stories reported in the incidents that reflect the complexity of service encounters.

To ensure integrity of data analysis, an inter-judge coding reliability test was performed on the final taxonomy using the percentage agreement index (PAI), defined as the proportion of the number of classification decisions that were in agreement 
compared to the total number of decisions made (Miles and Huberman, 1994, Stempel, 1955). A random sample of 100 coded utterances (i.e., words, phrases, sentences) was used to compute the PAI. After discussions of disagreements, the interjudge coding reliability coefficient was $94 \%$, which was deemed acceptable.

\section{RESULTS}

The data collection effort rendered 513 customer-reported service-encounter incidents. Content analysis of 513 customerreported service-encounter incidents yielded 3 meta-categories, 6 categories, and 33 sub-categories (see Figure 3 on page 7). Table 2 presents a description of the data in terms of the type of incidents and the type of services.

\begin{tabular}{|c|c|c|c|c|c|c|}
\hline \multirow[b]{3}{*}{ Type of Services } & \multicolumn{4}{|c|}{ Type of Incidents } & \multirow{2}{*}{\multicolumn{2}{|c|}{ Totals }} \\
\hline & \multicolumn{2}{|c|}{ Satisfactory Incidents } & \multicolumn{2}{|c|}{ Unsatisfactory Incidents } & & \\
\hline & $\underline{\mathrm{n}}$ & $\%$ & $\underline{\mathrm{n}}$ & $\%$ & $\underline{\mathrm{n}}$ & $\underline{\%}$ \\
\hline Product-related Services & 141 & 27.49 & 125 & 24.36 & 266 & $\overline{51.85}$ \\
\hline Pure Services & 129 & 25.15 & 118 & 23.00 & 247 & 48.15 \\
\hline Totals & 270 & 52.64 & 243 & 47.36 & 513 & 100 \\
\hline
\end{tabular}

Table 2. Description of the data in terms of type of incidents and type of services

Table 2 indicates that the sample collected for the study was more or less equally distributed in the type of services (i.e., product-related services and pure services) and type of incidents (i.e., satisfactory incidents and unsatisfactory incidents). Approximately equal representation was purposefully achieved to avoid biasing the results and to increase the generalizability of the results.

Of the 513 respondents who participated in the study, $50.49 \%(n=259)$ were female and $49.51 \%(n=254)$ were male. Table 3 provides a summary of other demographic information of the respondents who participated in this study.

\begin{tabular}{|c|c|c|c|c|c|}
\hline \multicolumn{3}{|c|}{ Age } & \multicolumn{3}{|c|}{ Education } \\
\hline & $\mathrm{n}$ & $\%$ & & $\mathrm{n}$ & $\%$ \\
\hline $18-29$ & 201 & 39.18 & High School & 50 & 9.75 \\
\hline $30-39$ & 171 & 33.34 & Some College & 183 & 38.21 \\
\hline $40-49$ & 94 & 18.32 & Associate Degree & 43 & 6.24 \\
\hline \multirow[t]{3}{*}{$50+$} & 47 & 9.16 & Bachelor's Degree & 142 & 27.68 \\
\hline & & & Graduate Degree & 85 & 16.18 \\
\hline & & & Other & 10 & 1.94 \\
\hline Total & 513 & 100 & Total & 513 & 100 \\
\hline
\end{tabular}

Table 3. Demographics of the respondents who participated in the study

A Chi-Square test of independence indicated that these demographic variables (i.e., gender, age, and education) did not have a relationship with satisfaction.

Of the respondents in the sample, 93\% (478 out of 513) reported the United States (US) as their place of residence. In order to determine representativeness, the sample was compared with the US online shopping population (see Table 4).

\begin{tabular}{|c|c|c|}
\hline \multirow{3}{*}{ Gender } & Study Sample & $\begin{array}{c}\text { US Online Shoppers } \\
\text { (Consumer Trends in Online } \\
\text { Shopping, 2001) }\end{array}$ \\
\hline & 49.51\% (Males) & $40 \%$ (Males) \\
\hline & $50.49 \%$ (Females) & $60 \%$ (Females) \\
\hline Education & 27.68\% (Bachelor) & $35 \%$ (4-Year College) \\
\hline Average Age & 34 (Approx.) & 42 \\
\hline
\end{tabular}

Table 4. Comparison of respondents with US online shoppers

The US online shopping population had a higher percentage of females than males, whereas the respondents in the study were more balanced. Thirty five percent of US online shoppers had a 4-year degree compared with $28 \%$ of the respondents in 
the study. Sixteen percent of the respondents in the study, however, earned a graduate degree, making $44 \%$ of the study respondents highly educated. Furthermore, $72 \%$ of the respondents in this study were between the ages of 18 and 39 , making the average age of the respondents somewhat younger than the US online shopping population. While not an exact match, the characteristics of the respondents for this study represented the US online shopping population fairly well.

The following is a brief explanation of the meta-categories and the major categories of the taxonomy.

Characteristics of the Core Services meta-category refers to the clusters of services fundamental for the service provider to conduct its core business on the Web. This meta-category comprised the following three categories:

- Core service delivery success/failure: refers to an incident that was classified by the respondent as satisfactory/unsatisfactory and included descriptions that were classified into one or more the sub-categories within the core service delivery success/failure category.

- Supporting services: refers to the type of services that assisted the service provider in the delivery of the core service.

- Information technology interface: refers to features related to the information technology interface used to interact with customers. In this case, it refers to the Web site.

Service provider characteristics and behaviors meta-category refers to the clusters of features and behaviors displayed by the service provider including the customer-contact employees. This meta-category comprised the following two categories:

- Perceived employee characteristics and behaviors: refers to the opinions and perceptions that customers formed about the service provider employees during their interactions within an incident.

- Trust: refers to the willingness of the respondent to become vulnerable to the service provider (McKnight and Chervany, 2002).

It is worth noting that two of the four trust sub-categories initially considered (i.e., disposition to trust, trusting intentions) could not be reliably extracted from the customer-reported descriptions of incidents since the questions in the survey instrument were not devised to specifically elicit dispositional and intentional information. These latent constructs (i.e., disposition to trust, trusting intentions) necessitated a great deal of inference to identify the customers' descriptions that represented such concepts. Some respondents reported within the incidents about the security of transactions (i.e., institutionbased trust) and the integrity of service providers (i.e., trusting beliefs) when dealing with online service providers. For the sake of parsimony, however, two sub-categories were created within the trust category and were described by respondents as being either positive or negative.

Customer's characteristics and behaviors refer to the clusters of features and behaviors displayed by the customer. This meta-category comprised the customer's situation before the encounter category. 

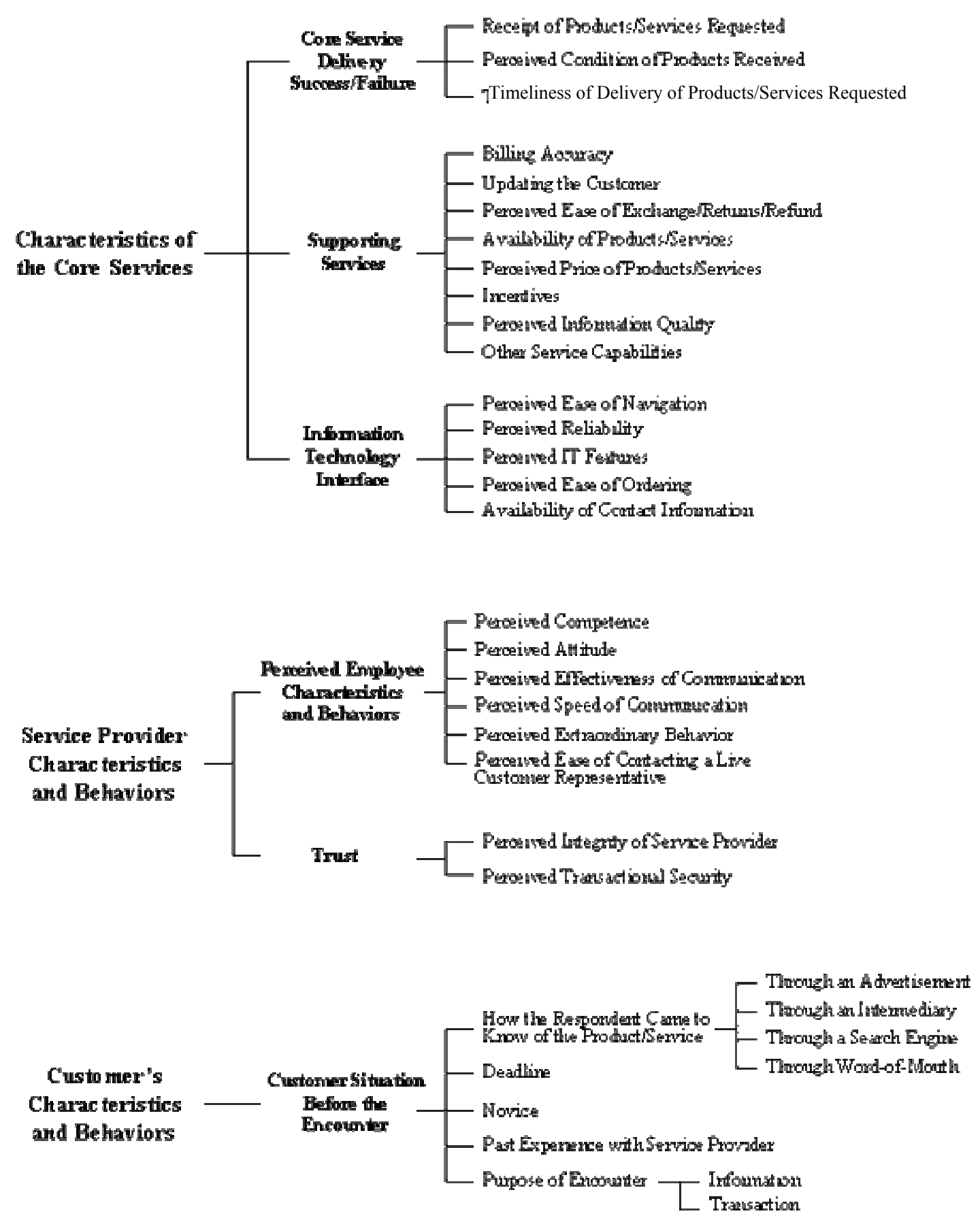

Figure 3. Antecedents of customer satisfaction with electronic service encounters 
Table 5 below presents a summary of the frequencies and percentages of incidents that were classified within each of the subcategories of the taxonomy.

\begin{tabular}{|c|c|c|c|}
\hline Categories & $\begin{array}{l}\text { Frequency } \\
\text { (\% of total } \\
\text { incidents) }\end{array}$ & $\begin{array}{c}\text { Satisfactory } \\
\text { Incidents ( } \% \\
\text { of Category) }\end{array}$ & $\begin{array}{c}\text { Unsatisfactory } \\
\text { Incidents (\% of } \\
\text { Category) } \\
\end{array}$ \\
\hline \multicolumn{4}{|l|}{ Core Service Delivery Success/Failure Category } \\
\hline Receipt of Products/Services Requested & $463(90.25 \%)$ & $233(50.32 \%)$ & $230(49.68 \%)$ \\
\hline Perceived Condition of Products Received & $57(11.11 \%)$ & $38(66.67 \%)$ & $19(33.33 \%)$ \\
\hline Timeliness of Delivery of Products/Services Requested & $131(25.54 \%)$ & $85(64.89 \%)$ & $46(35.11 \%)$ \\
\hline \multicolumn{4}{|l|}{ Supporting Services Category } \\
\hline Billing Accuracy & $52(10.14 \%)$ & $7(13.46 \%)$ & $45(86.54 \%)$ \\
\hline Updating the Customer & $121(23.59 \%)$ & $75(61.98 \%)$ & $46(38.01 \%)$ \\
\hline Availability of Products/Services & $60(11.70 \%)$ & $34(56.67 \%)$ & $26(43.33 \%)$ \\
\hline Perceived Price of Products/Services & $59(11.50 \%)$ & $50(84.75 \%)$ & $9(15.25 \%)$ \\
\hline Incentives & $51(9.94 \%)$ & $31(60.78 \%)$ & $20(39.22 \%)$ \\
\hline Perceived Ease of Exchange/Returns/Refunds & $81(15.79 \%)$ & $14(17.28 \%)$ & $67(82.72 \%)$ \\
\hline Perceived Information Quality & $65(12.67 \%)$ & $28(43.08 \%)$ & $37(56.92 \%)$ \\
\hline Other Service Capabilities & $95(18.52 \%)$ & $78(82.11 \%)$ & $17(17.89 \%)$ \\
\hline \multicolumn{4}{|l|}{ Information Technology Interface Category } \\
\hline Perceived Ease of Navigation & $80(15.59 \%)$ & $70(87.50 \%)$ & $10(12.50 \%)$ \\
\hline Perceived Ease of Ordering & $38(7.40 \%)$ & $35(92.11 \%)$ & $3(7.90 \%)$ \\
\hline Perceived Reliability & $21(4.09 \%)$ & $6(28.57 \%)$ & $15(71.43 \%)$ \\
\hline Perceived IT Features & $18(3.51 \%)$ & $7(38.89 \%)$ & $11(61.11 \%)$ \\
\hline Availability of Contact Information & $13(2.53 \%)$ & $2(15.38 \%)$ & $11(84.62 \%)$ \\
\hline \multicolumn{4}{|l|}{ Customer's Situation before the Encounter Category } \\
\hline \multicolumn{4}{|l|}{ How respondent came to know of product/service } \\
\hline Through an advertisement & $35(6.82 \%)$ & $17(48.57 \%)$ & $18(51.43 \%)$ \\
\hline Through a search engine & $19(3.70 \%)$ & $13(68.42 \%)$ & $6(31.58 \%)$ \\
\hline Through an intermediary & $30(5.85 \%)$ & $10(33.33 \%)$ & $20(66.67 \%)$ \\
\hline Through word-of-mouth & $14(2.73 \%)$ & $7(50 \%)$ & $7(50 \%)$ \\
\hline Deadline & $65(12.67 \%)$ & $28(43.08 \%)$ & $37(56.92 \%)$ \\
\hline Novice & $17(3.31 \%)$ & $8(47.06 \%)$ & $9(52.94 \%)$ \\
\hline Past Experience with Service Provider & $52(10.14 \%)$ & $31(59.62)$ & $21(40.38)$ \\
\hline \multicolumn{4}{|l|}{ Purpose of Encounter } \\
\hline Information & $50(9.75 \%)$ & $37(74 \%)$ & $13(26 \%)$ \\
\hline Transaction & $463(90.25 \%)$ & $233(50.32 \%)$ & $230(49.68 \%)$ \\
\hline \multicolumn{4}{|l|}{ Employee Characteristics and Behavior Category } \\
\hline Perceived Competence & $18(3.51 \%)$ & $4(22.22 \%)$ & $14(77.78 \%)$ \\
\hline Perceived Attitude & $85(16.57 \%)$ & $35(41.18 \%)$ & $50(58.82 \%)$ \\
\hline Ease of Contacting Live Customer Representative & $106(20.66 \%)$ & $22(20.75 \%)$ & $84(79.25 \%)$ \\
\hline Perceived Effectiveness of Communication & $69(13.45 \%)$ & $13(18.84 \%)$ & $56(81.16 \%)$ \\
\hline Perceived Speed of Communication & $33(6.43 \%)$ & $20(60.61 \%)$ & $13(39.39 \%)$ \\
\hline Perceived Extraordinary Behavior & $16(3.12 \%)$ & $9(56.25 \%)$ & $7(43.75)$ \\
\hline \multicolumn{4}{|l|}{ Trust Category } \\
\hline Perceived Integrity of Service Provider & $40(7.80 \%)$ & $5(12.50 \%)$ & $35(87.50 \%)$ \\
\hline Perceived Transactional Security & $30(5.85 \%)$ & $28(93.33 \%)$ & $2(6.67 \%)$ \\
\hline
\end{tabular}

Table 5. Summary of the frequencies and percentages of incidents classified within each of the sub-categories of the taxonomy 
Table 5 reveals that receipt of products/services requested was the most frequently reported sub-category within the core service delivery success/failure category. Approximately 50\% of respondents reported being satisfied when they received the correct book, booked hotels/flights, paid the bills online, and traded stocks online successfully. On the hand, approximately the same percentage of respondents reported unsatisfactory incidents when they received the wrong book or experienced problems when booking a flight/hotel, paying bills online, or trading stocks online.

Furthermore, approximately 26\% (131 out of 513) of incidents reported timeliness of products/services requested. Out of these 131 incidents, $65 \%$ (85 out of 131) were reported in satisfactory incidents while 35\% (46 out 131) were reported in unsatisfactory incidents. This implies that respondents were approximately twice as much more likely to report an incident as unsatisfactory when they did not receive a book on time or experienced delays when trading stocks or paying bills online than when they received a book on time or experienced no delays when trading stocks or paying bills online.

Within the supporting services category, updating the customer was the most frequently reported sub-category. Approximately, 62\% (75 out of 121) of incidents reported being satisfied when they were updated of the different stages leading to the completion of a transaction (e.g., order confirmation, shipping confirmation, confirmation that stock was bought/sold, confirmation of bill payment, confirmation of airline/hotel/concert reservation) or of any changes that may arise before the completion of a transaction (e.g., item no longer in stock, airline can no longer issue eticket, concert cancelled).

It worth noting that within the supporting services category, approximately $85 \%$ (45 out of 52) of respondents reported an incident as unsatisfactory when they were incorrectly billed, billed twice, or billed for products/services not delivered/rendered. Within the bricks-and-mortar context, billing is less of a concern since customers are able to verify whether they were correctly charged for the products or services bought/rendered. If there is an incorrect billing, customers have the ability to return to the service provider to rectify the problem.

Within an online context, on the other hand, customers must solely rely on online service provider not only for correct billing but also for delivery of the requested product or service. Respondents complained about the effort and the time it took to resolve billing problems when they occurred. Online service providers must therefore strive to correctly bill customers for the requested products or services only.

Furthermore, $85 \%$ of respondents (50 out of 59) reported an incident as satisfactory when they perceived the price of a product or service to be low, fair, or inexpensive. This suggests that even though price alone was not the most important factor within the supporting services category, some respondents still enjoy and look for bargains on the Web.

Table 5 also indicates that perceived ease of navigation was the most frequently reported sub-category within the information technology interface while deadline was the most frequently mentioned sub-category within the customer's situation before the encounter.

Within the employee characteristics and behavior category, ease of contacting a live customer representative and perceived attitude were the most frequently mentioned sub-categories. Approximately $79 \%$ (84 out of 106) of the incidents complained about the difficulty of reaching a live customer representative, and 59\% (50 out of 85) of incidents complained that customercontact employees were unfriendly, unprofessional, unpleasant, impolite, uncaring, impatient, unhelpful, impersonal, or negative. Respondents also mentioned that the customer representative tried to put the blame on them.

Within the bricks-and-mortar context, the employee characteristics and behavior category has been deemed as crucial in service encounters since customers interact face-to-face with sales personnel and customer representatives (Bitner et al., 1990, Heckman and Guskey, 1998). This category also appears to be significant in service encounters within the electronic context. This category may very well be an important generic category present in all types of service encounters within the bricks-and-mortar context (Heckman and Guskey, 1998) and the electronic context.

\section{IMPLICATIONS}

Inspired by the well-established service-encounter literature in the bricks-and-mortar context and by the electronic commerce literature, three meta-categories and six categories were identified as antecedents of customer satisfaction with electronic service encounters. This study therefore offered an insight into specific events that contributed to the satisfaction or dissatisfaction of customers when they engaged in transactions with online service providers, providing a deeper understanding of the complexities involved in conducting business on the Internet.

The original taxonomy developed by Bitner and colleagues (1990) comprised three main concepts: core service failures, customization, and employee behaviors. Since then, the original taxonomy has proven to be robust and valid across different industries, across respondents, and across different classification schemes. The findings of this study suggested that three major categories identified by Bitner and colleagues (1990) are robust, even in the electronic context of the Internet. 
The taxonomy developed in this study was compared with taxonomies (e.g., Bitner et al., 1990; Heckman \& Guskey, 1998) developed in previous service-encounter studies. The meta-category characteristics of the core service included core service delivery success/failure, a category that was similar in concept to core service delivery failures category. This meta-category also included a supporting services category and an IT interface category, both of which assist the core service. This metacategory may be more inclusive than the core service delivery failures category and may motivate future research on other characteristics of the core service that may contribute to customer satisfaction with electronic service encounters.

Similarly, the meta-category service provider characteristics and behaviors included perceived employee characteristics and behaviors, a category that was similar in concept to the employee behaviors category. This meta-category also included a trust category that referred to characteristics of the service provider as well as customer-contact employees. This metacategory may be more inclusive than employee behaviors category and may motivate future research on other characteristics of the service provider that contribute to customer satisfaction with online service encounters.

The meta-category customer's characteristics and behaviors included customer's situation before the encounter, a category similar in concept to the customization category. This meta-category may be more inclusive and may motivate future research on customer's inherent characteristics that may contribute to the satisfaction of online service encounters.

This study identified a taxonomy of antecedents of customer satisfaction with business-to-customer transactions in an electronic environment. This taxonomy therefore offered an insight into the specific events that contributed to the satisfaction or dissatisfaction of customers when they engaged in transactions with online service providers. Future studies seeking to acquire a more holistic view of commerce on the Internet (e.g., business-to business) will be well served to use this taxonomy as an initial framework.

\section{REFERENCES}

1. Bitner, M. J., Booms, B. H. and Tetreault, M. S. (1990) The service encounter: Diagnosing favorable and unfavorable incidents Journal of Marketing, 54, 71-84.

2. Collier, D. A. and Meyer, S. M. (1998) A service positioning matrix International Journal of Operations \& Production Management, 18, 1223-1244.

3. Flanagan, J. C. (1954) The critical incident technique Psychological Bulletin, 51, 327-355.

4. Gefen, D. (2000) E-commerce: The role of familiarity and trust Omega, 28, 725-737.

5. Gefen, D. (2002) Customer loyalty in e-commerce Journal of the Association for Information Systems, 3, 27-51.

6. Gefen, D., Karahanna, E. and Straub, D. (2003) Trust and TAM in online shopping: An integrated model MIS Quaterly, 27, 51-90.

7. Gremler, D. and Bitner, M. J. (1992) In Marketing Theory and Applications, Vol. 3 (Eds, Allen, C., Madden, T., Shimp, T., Howell, R., Zinhan, G., Heisley, D., Semenik, R., Dickson, P., Zeithaml, V. and Jenkins, R.) AMA Winter Educators' Conference, pp. 111-118.

8. Gronroos, C. (1990) Services Management and Marketing: Managing the Moments of Truth in Service Competition, Lexington Books, Lexington, MA.

9. Grove, S. and Fisk, R. (1997) The impact of other customers on service experiences: A critical incident examination of "getting along" Journal of Retailing, 73, 63-85.

10. Heckman, R. and Guskey, A. (1998) Sources of customer satisfaction and dissatisfaction with information technology help desks Journal of Market Focused Management, 3, 59-91.

11. Javenpaa, S. L. and Tractinsky, N. (1999) Consumer trust in an internet store: A cross-cultural validation Journal of Computer-Mediated Communication, 5.

12. Johnson, L. J. (1999) In William F. Harrah College of Hotel AdministrationUniversity of Nevada, Las Vegas, pp. 174.

13. Keaveney, S. M. (1995) Customer switching behavior in service industries: An exploratory study Journal of Marketing, 59, 71-82.

14. Kelley, S., Hoffman, D. and Davis, M. (1993) A typology of retail failures and recoveries Journal of Retailing, 69, 429-452.

15. Kenny, D. and Marshall, J. (2000) Contextual marketing: The real business of the Internet Harvard Business Review, 78, 119-125. 
16. Klein, L. R. (1998) Evaluating the potential of interactive media through a new lens: Search versus experience goods Journal of Business Research, 41, 195-203.

17. Lovelock, C. H. (1983) Classifying services to gain strategic marketing insights Journal of Marketing, 47, 9-20.

18. McKnight, H. and Chervany, N. (2002) What trust means in e-commerce customer relationships: An interdisciplinary conceptual typology International Journal of Electronic Commerce, 6, 35-59.

19. Miles, M. and Huberman, A. (1994) Qualitative Data Analysis, Sage, CA.

20. Mohr, L. A. and Bitner, M. J. (1995) The role of employee effort in satisfaction with service transactions Journal of Business Research, 32, 239-252.

21. Morgan, R. and Hunt, S. (1994) The commitment-trust theory of relationship marketing Journal of Marketing, 58, 20-38.

22. Oliver, R. (1997) Satisfaction: A Behavioral Perspective on the Consumer, McGraw-Hill, Inc., New York.

23. Oliver, R. (1999) Whence consumer loyalty? Journal of Marketing, 63, 33-44.

24. Peterson, R. A., Balasubramanian, S. and Bronnenberg, B. J. (1997) Exploring the implications of the Internet for consumer Marketing Journal of the Academy of Marketing Science, 25, 329-346.

25. Reichheld, F. and Schefter, P. (2000) E-Loyalty: Your secret weapon on the Web Harvard Business Review, 78, 105-113.

26. Romano, N. and Fjermestad, J. (2001-2002) Electronic commerce customer relationship management: An assessment of Research International Journal of Electronic Commerce, 6, 61-114.

27. Ronan, W. W. and Lathan, G. P. (1974) The reliability and validity of the critical incident technique: A closer look Studies in Personnel Psychology, 6, 53-64.

28. Schmenner, R. W. (1986) How can service businesses survive? Sloan Management Review, 27, 21-32.

29. Sheth, J. and Parvatiyar, A. (1995) Relationship in consumer markets: Antecedents and consequences Journal of Academy of Marketing Science, 23, 255-271.

30. Shostack, L. (1985) In The Service Encounter(Eds, Czepiel, J., Solomon, M. and Surprenant, C.) Lexington Books, Lexington, MA, pp. 243-254.

31. Stempel, G. (1955) Increasing reliability in content analysis Journalism Quarterly, 19, 449-455.

32. Wemmerlov, U. (1990) A taxonomy for service processes and its implications for system design International Journal of Service Industry Management, 1, 24-35. 